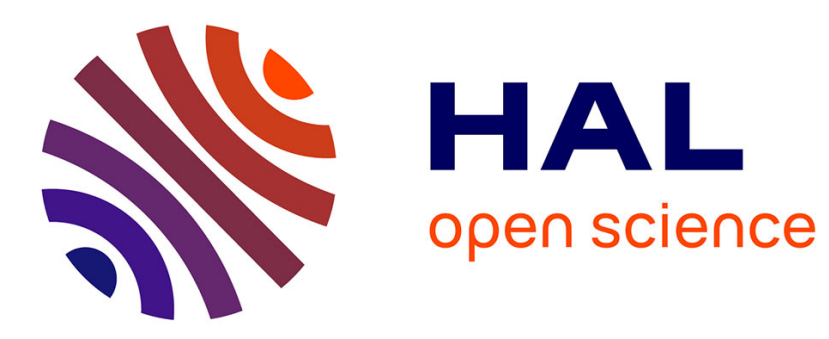

\title{
Distributed Interactive Surfaces: A step towards the distribution of tangible and virtual objects
} Sophie Lepreux, Sébastien Kubicki, Christophe Kolski, Jean Caelen

\section{To cite this version:}

Sophie Lepreux, Sébastien Kubicki, Christophe Kolski, Jean Caelen. Distributed Interactive Surfaces: A step towards the distribution of tangible and virtual objects. José A. Gallud; Ricardo Tesoriero; Victor M.R. Penichet. Distributed User Interfaces: Designing Interfaces for the Distributed Ecosystem, Springer, pp.133-143, 2011, 978-1-4471-2270-8. 10.1007/978-1-4471-2271-5_15 . hal-00864267

\section{HAL Id: hal-00864267 https://hal.science/hal-00864267}

Submitted on 20 Sep 2013

HAL is a multi-disciplinary open access archive for the deposit and dissemination of scientific research documents, whether they are published or not. The documents may come from teaching and research institutions in France or abroad, or from public or private research centers.
L'archive ouverte pluridisciplinaire HAL, est destinée au dépôt et à la diffusion de documents scientifiques de niveau recherche, publiés ou non, émanant des établissements d'enseignement et de recherche français ou étrangers, des laboratoires publics ou privés. 


\title{
Distributed Interactive Surfaces
}

\section{A step towards the distribution of tangible and virtual objects}

\author{
Sophie Lepreux $^{(1)}$, Sébastien Kubicki ${ }^{(1)}$, Christophe Kolski ${ }^{(1)}$, Jean Caelen ${ }^{(2)}$ \\ ${ }^{(1)}$ Université Lille Nord de France, F-59000 Lille, France \\ ${ }^{(1)}$ UVHC, LAMIH, F-59313, Valenciennes, France \\ ${ }^{(1)} \mathrm{CNRS}$, FRE 3304, F-59313 Valenciennes, France \\ (1) \{firstname.name\}@univ-valenciennes.fr \\ ${ }^{(2)}$ Multicom, Laboratoire d Informatique de Grenoble (LIG), \\ UMR 5217, BP53 F-38041 Grenoble cedex 9, France. \\ ${ }^{(2)}\{$ firstname.name\}@imag.fr
}

\begin{abstract}
After having outlined the uses of new technologies such as smartphones, touchscreen tablets and laptops, in this paper we present the TangiSense interactive table, equipped with RFID technology tagged on tangible objects, as new paradigm of interaction for ambient intelligence. We propose a problem space and some scenarios illustrating the distribution of user interfaces within the framework of collective work. A case study centered on crisis management units, i.e. a collaborative situation, with multiple actors who are geographically separate, makes it possible to illustrate possible distributed uses and the TangiSense $\mathrm{s}$ capacities. To finish, the chapter presents the directions under consideration for our future research.
\end{abstract}

\section{INTRODUCTION}

New interactive surfaces such as touchscreen tablets are currently being studied a lot. These surfaces allow interactions based on tactile technology. The principal uses of the tablets are: Internet access, consultation of books, and visualization of films or photographs. Smartphones, being smaller and thus more mobile, and also having access to the Internet even though with less ease of navigation due to the size of the screen, are used when there is a need for mobility. As for laptop computers, they are increasingly small (e.g. netbooks), but they remain the least mobile and thus are used mainly in fixed situations. They allow a wider range of activities than the tablets, such as the easy use of an editor for text documents, or 
running applications which necessitate more resources. We propose in this chapter to increase another technology to this range of products: the Interactive Table (Fig. 1).

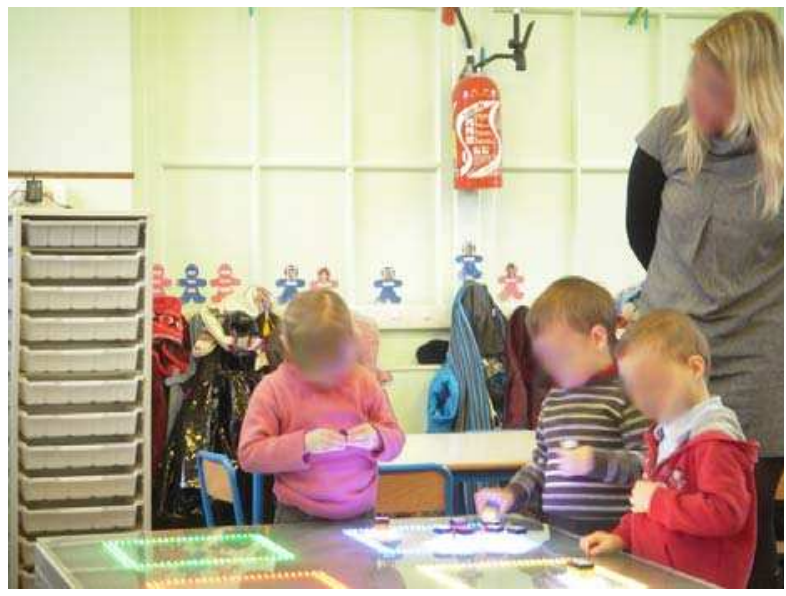

Fig. 1 The TangiSense interactive table with the Recognition and learning of colors application

Interactive tables have existed for a few years now. They are similar to the touchscreen tablet, but larger, being more the size of a coffee table for example, around $1 \mathrm{~m}$ square. These tables are mainly based on tactile or vision technology and allow the same uses as the tablets; they thus handle mainly virtual objects. In this chapter, we propose another type of interactive table which uses Radio Frequency Identification (RFID) technology in order to interact, not only with the fingers on virtual objects but directly with tangible objects RFID tagged. This table, called TangiSense, detects objects equipped with RFID tags when they are placed on it [3]. The use of RFID makes it possible firstly to detect objects present on the surface of the table, secondly to identify them thanks to one or more tags stuck underneath the object (because RFID tags are unique), and finally to store information directly in these objects or to superimpose them. It is thus possible to work with a set of objects on a table, to store data in these objects (for example their last position or their possible owner) in order to subsequently be able to reuse them on another table at another moment and with your own embedded information (example: the last state of a game of chess). The interaction is done completely by these objects and this can influence virtual objects (which cannot be directly manipulated). It provides different uses of the other technologies presented before because it uses the RFID characteristic as well as the advantage of tangible interaction [1]. For example, this table was used in a school class with children to learn and recognize colors (Cf. Fig. 1) [5], in a museum to associate animals (tangible objects) to their virtual environment, etc. From these four interactive technologies, we note that currently the systems are mainly centered on a one at a time type of usage. The users can use one system or another in turn but they rarely share the use over two or more systems. In this chapter, an application is shared 
between several users, and several platforms using several types of interaction. In this context, the user interface (UI) becomes distributed.

The arrival of mobile platforms such as the PDA, smartphones and others has been the subject of many research projects. The objective is to facilitate the migration of applications when the context changes. The user wanted to be able to move from one platform to another one without loss of coherence in the use of his/her application, without loss of data (e.g. he/she wanted to continue to deal with his/her e-mails or surf on Internet while being mobile). The Cameleon model became a framework for the modeling /transformation of the HCI [2]. Within this framework, the transformation is done according to the characteristics of a context, i.e. of a user, a platform and an environment, whereas our goal is to extend this work to the simultaneous use of several users (collaborative context), several platforms and consequently several environments [4]. The users wish to share information and interfaces with other users, not necessarily using the same platform, not having the same needs/constraints. These problems based only on the virtual have already been approached by Tandler [9].

This chapter concerns tangible interactions on tabletop and distribution with several platforms (or surfaces). The section 1 proposes a problem space and four scenarios illustrating the functioning of interactions between platform with and without tangible objects. Then the section 2 presents a case study implying several users in several geographically distributed environments and using different types of platform. This case study allows illustrating the UI composition.

\section{Interaction with tangible and/or virtual objects to distribute UI}

A framework is necessary to propose scenarios. This framework is a problem space of distribution adapted to interactive surfaces using tangible or virtual objects.

\section{Definition of problem space for the distribution of $U I$}

The proposed problem space is composed of 5 dimensions and considers 3 types of platform:

- Mixed platforms i.e. manipulating tangible and virtual objects (e.g. The TangiSense tabletop) (MP),

- Platforms using only tangible objects (e.g. the TangiSense Tablet) (TP),

- Platforms using only virtual objects (e.g. IPad, Smartphone) (VP).

The dimension 1 positions the source platform which starts the collaboration between supports. The dimension 2 concerns the target platform which is contacted to collaborate. It integrates information provided by the source platform. The 
possible values are $\{M P, T P, V P\}$ and Multiple if there are several and different target platforms. The Dimension 3 is the distribution strategy which could have two values (these strategies are more detailed in [6]):

Centralized: the interactive tabletop is declared to be the master and the other devices are slaves. In this case, the table manages the information transfer according to the objectives of each platform and it centralizes all the information available in the distributed system (Cf. Fig. 2a)). The master table takes responsibility for choosing the adequate mode of representation to transmit to the target platform. For instance, the placement of an object on the master table which represents a choice is represented by a list on the smartphone concerned by this choice. The users use objects on the master table in order to connect it to other platforms and select the UI to share. This strategy is useful when the UI is complete on one support with priority and if UI has to be distributed on other supports. The disadvantage of this strategy is that breakdowns are not tolerated.

$\square$ Distributed: all the platforms are autonomous and at the same decision level (Cf. Fig. 2b)). The set forms a graph where $\mathrm{n}$ corresponds to the number of distributed interfaces (in Fig. 2b, n=9). Here, a relation between two platforms means a distributed interface. There can be several functions of relation. Either the two parts of user interfaces are complementary, or there are common parts to both interfaces. As an interface can be linked to several others, it must compose the set of the concerned interfaces. For example if an interface is linked to 3 others following the functions $\mathrm{f} 1, \mathrm{f} 2$ and $\mathrm{f} 3$, then $\mathrm{U}=\mathrm{f} 1(\mathrm{UI} 1)+\mathrm{f} 2(\mathrm{UI} 2)+\mathrm{f} 3(\mathrm{UI} 3)$. The functions could be, for example, ensemblist relations [7] or distribution primitives as proposed in [8]. The interesting functions for the distribution and collaboration are complete duplication, partial duplication, the part extraction, etc. In this case, each platform must manage several UIs distributed with several platforms. When the user needs to move or to share a UI with another user, the platforms have to connect and the UIs (have to be deployed according to the local context (Platform, User, Environment).

The dimension 4 informs on UI distribution (complete or partial). This dimension indicates if the whole source platform interface is distributed on target platform or if a part is shared. By part, we consider visual part i.e. an extract of a tabletop area or business part i.e. task information and business functionality are shared/distributed. The value can be \{Full application, Part of interface or Multiple $\}$, i.e. can be different for each target platform.

The dimension 5 concerns the synchronization. This dimension allows taking into account the synchronous or asynchronous collaborations. If the value is synchronous, the platforms are connected and the modifications on one platform are reflected in real time in other(s) platform(s). In asynchronous case, users work on platform source, other ones on target platform. At a given time, they want to synchronize the two (or more) platforms containing their separate works in order to confront/fusion their production/point of view (collaborate). The problem space is 
represented on Fig. 3, on which scenarios, described in the following section, are positioned.

a)
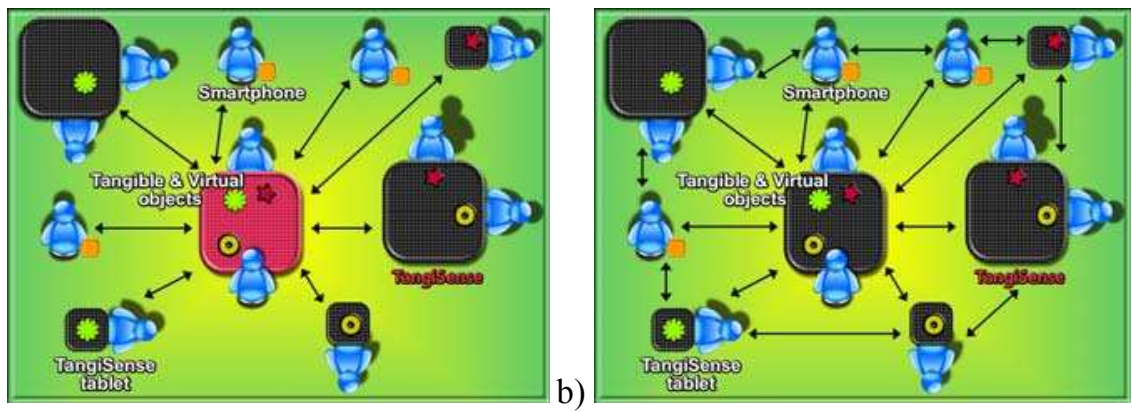

Fig. 2. a) Centralized distribution of UI b) Network of Distributed UI

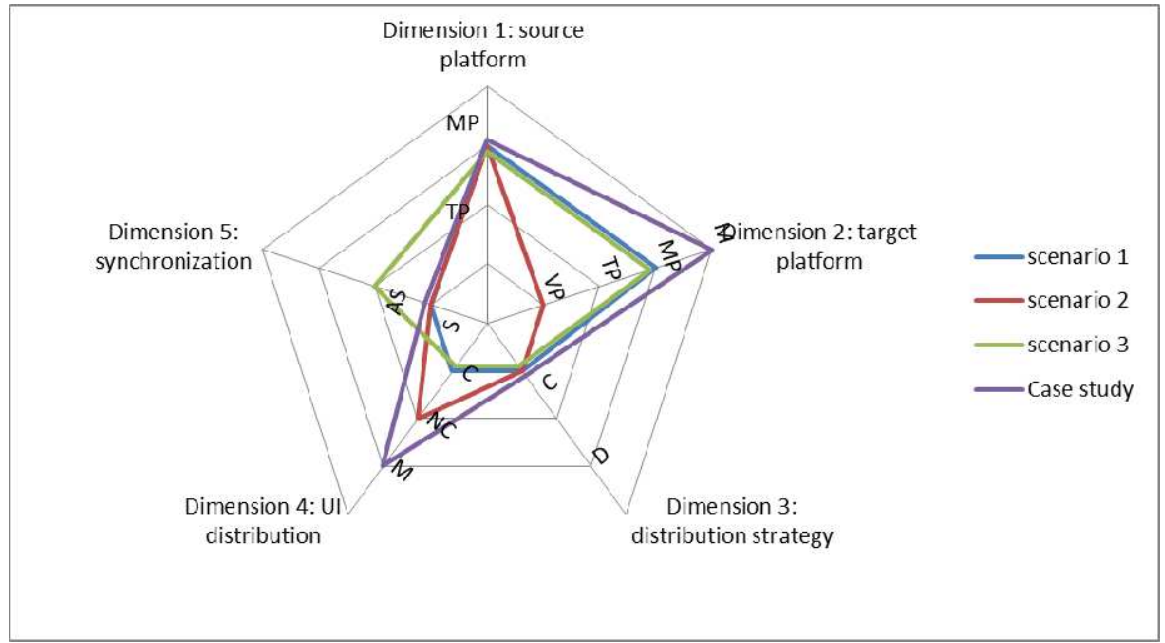

Fig. 3. Problem space and positionning of 4 representative scenarios.

\section{Scenarios of interaction initiated by tangible objects on tabletop}

Four scenarios illustrate the using of tangible objects to collaborate between several platforms. The scenario 1 implicates two users (user1 and user2) who work on two Mixed Platforms (MP) named respectively Table1 and Table2 (which can be TangiSense tabletops), following a centralized strategy. The distribution is complete and synchronous. The sequence diagram in Fig. 4 illustrates the collaboration starting initiated by User1 on Table1.

Another scenario (Fig. 5) implicates a Virtual Platform (VP) as target. In this case, the representation of tangible objects has to be virtual objects. The user of 
virtual platform could be suggested modifications of tangible object position. In this scenario, the collaboration is partial; functionality is concerned by the distribution.

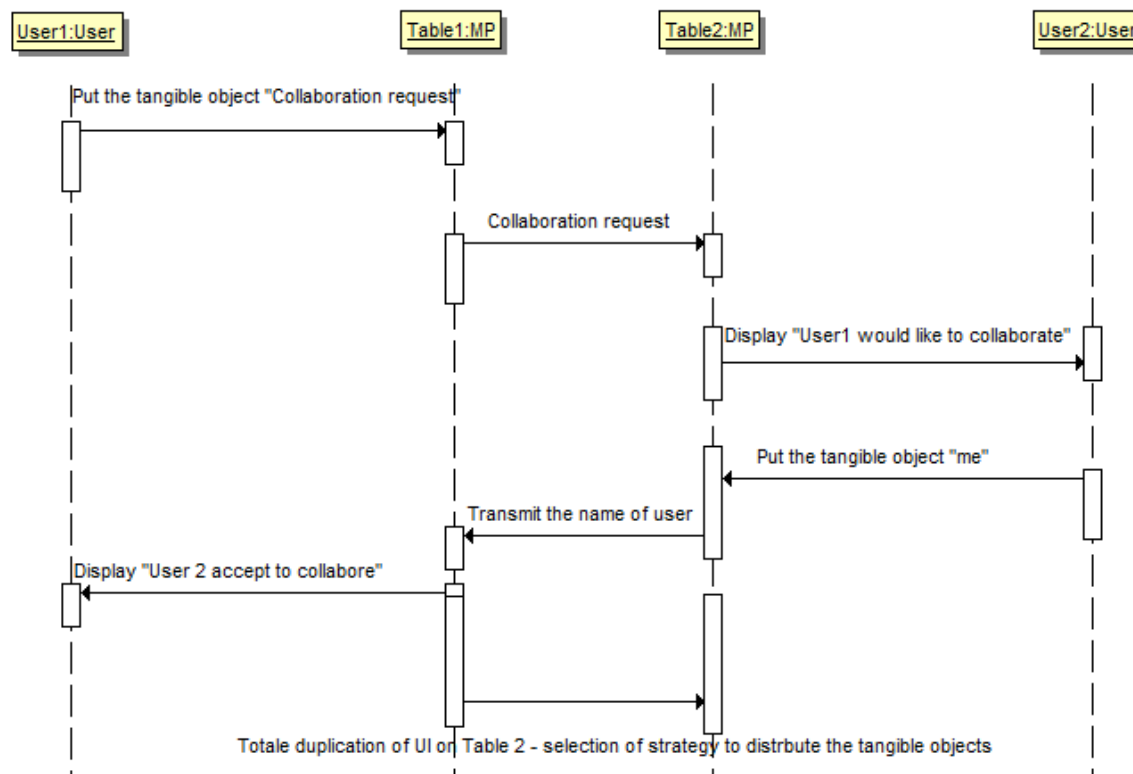

Fig. 4. Sequence diagram illustrating the scenario 1

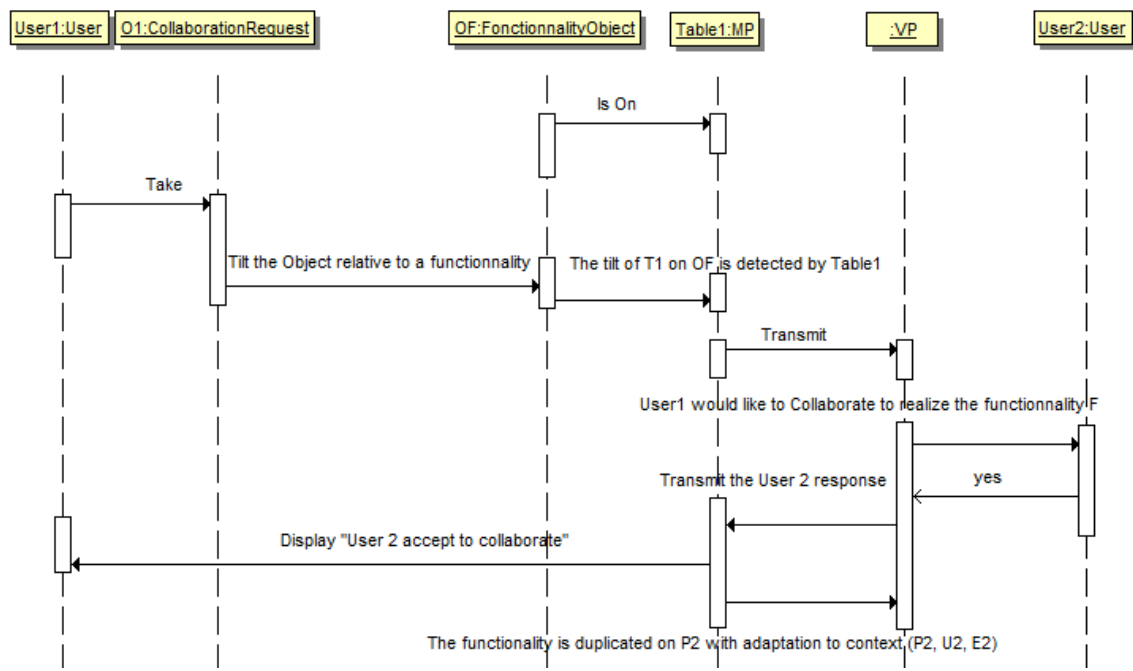

Fig. 5. Sequence diagram to illustrate the scenario 2 (partial duplication of functionality on VP)

The third scenario (Fig. 6) begins by exchanges between users collaborating in situated manner on geographically distributed platforms. The synchronization al- 
lows, at a given time, to distribute the collaboration between the whole users/platforms.

Then, the last representative scenario (Fig. 9) puts in relation several and different platforms (the source platform is in our research always a MP as TangiSense tabletop). The value concerning the complete UI dimension is multiple because it could be different following situations and platforms. This scenario is a composition of scenarios presented before and is developed in the realistic case study in the following section.

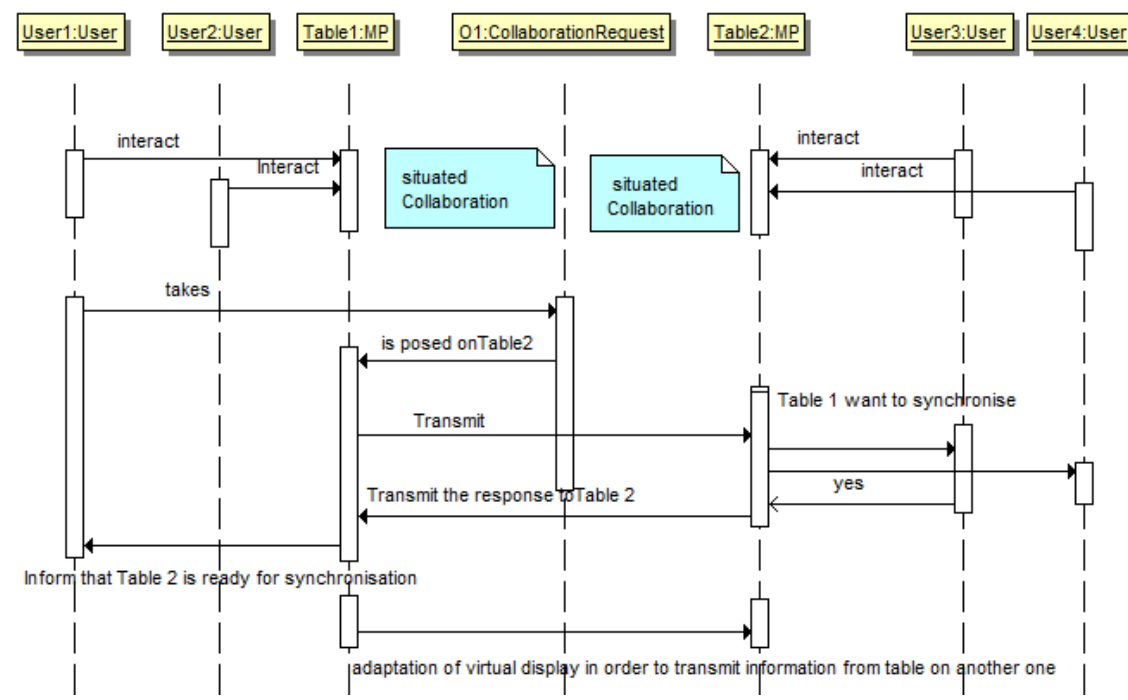

Fig. 6. Sequence diagram to illustrate the scenario 3 (asynchronous collaboration)

\section{Case study: Crisis management unit}

This case study presents a possible use of the table, of the tangible and/or virtual objects associated and of various devices used by several users in the case of a crisis management unit. When a significant event such as a forest fire occurs, the people concerned are not together. Some are located at a place where information is centralized; supervisors/decision makers are to be found among them. They collect information from other actors who are geographically separated on the ground, concerning elements such as the state of the fire, its propagation velocity and the direct implications. The crisis unit makes decisions based on the collected information and must transmit them to the on-site teams. They are also in contact with other structures such as the police officers who must, according to the case, prohibit access to certain zones or warn/evacuate the potential disaster victims. The state of the system at one given moment with an example of use per device and actor is shown in Fig. 7. This figure shows a centralized version of crisis 
management. It is the table which manages the interfaces and which transmits the UI to the other platforms according to, for example, the scenario given previously. Indeed in this context, the whole of the interfaces is available on the interactive table which is master. The other platforms are considered as children of this table and collect the UIs that the master table authorizes to share. In this case, it is the master table which combines according to the need of interfaces.

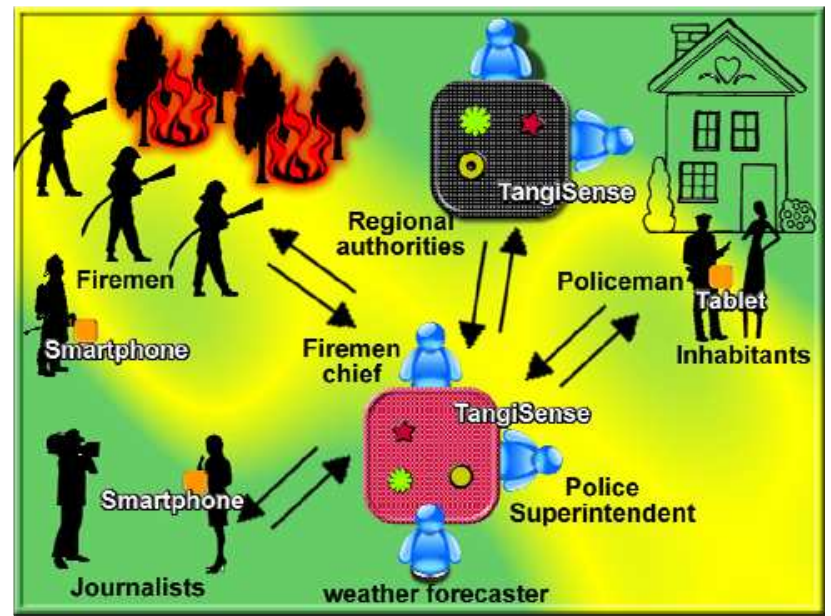

Fig. 7. Crisis unit using TangiSense and other platforms

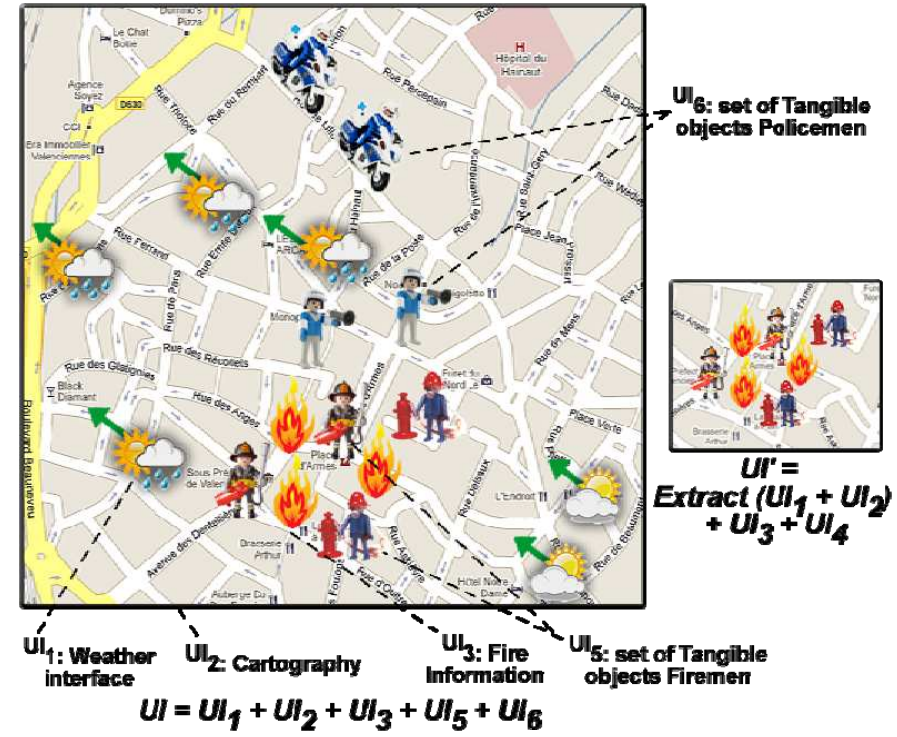

Fig. 8. Examples of DUI 


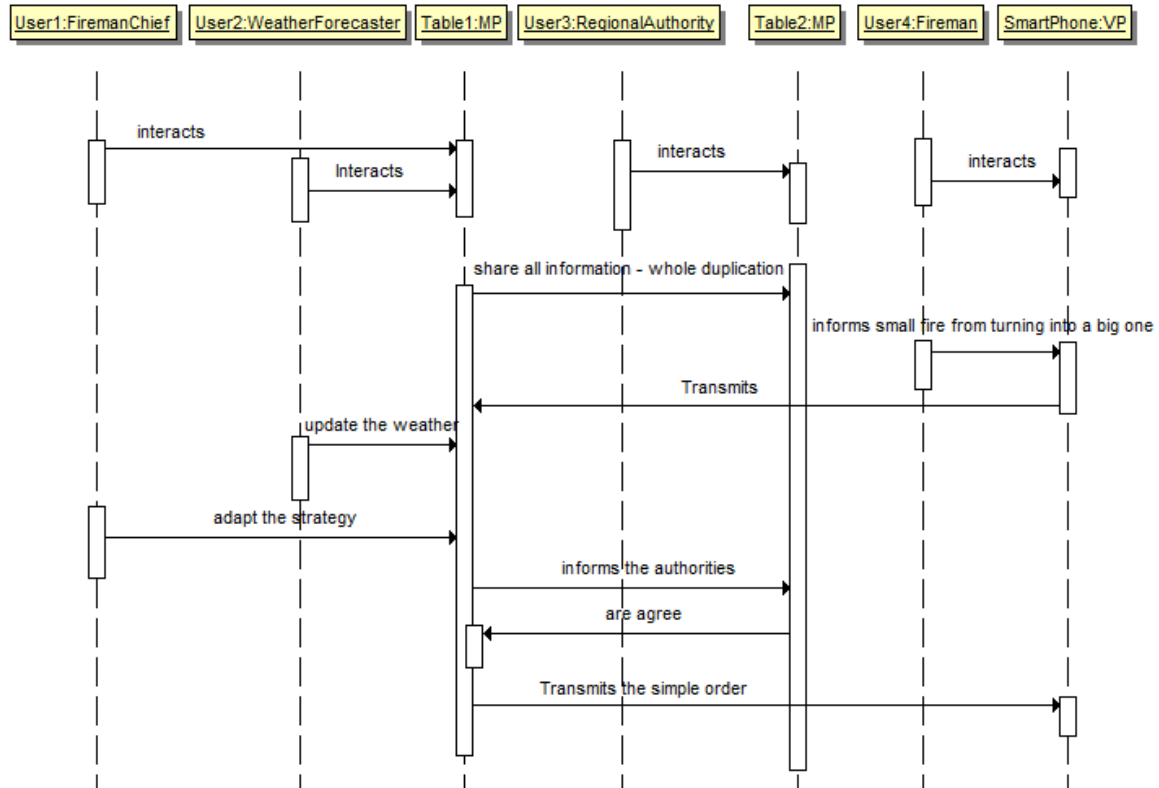

Fig. 9. Sequence diagram to illustrate an example of exchange in the case study (Multiple Collaboration)

Given: an interface UI1 dedicated to the weather, UI2 dedicated to the cartography, UI3 and UI4 two UIs dedicated to the firemen, UI5 tangible objects dedicated to the placement of firemen and UI6 tangible objects dedicated to the placement of police officers. An interface $U$ on a master table is visible on Fig. 8 while $U^{\prime}$ is the distributed part presented to the firemen. The Fig. 9 illustrates by a sequence diagram exchanges between these users: Fireman Chief, Weather Forecaster using a Mixed Platform (TangiSense), the Regional Authority agent who interacts with another Mixed Platform and Fireman who uses Smartphone. These three groups of persons are distributed. The two tables share the same and whole UI. When the fireman chief proposes a strategy on table1, if this strategy is validated by the regional Authority on table 2, then the information is transmitted to the concerned fireman. In a same way, when a fireman who is on place, is aware of a situation changing, he transmits the information (intended for his chief) via his smartphone on the table 1. This information is updated on table 2.

\section{CONCLUSION \& PROSPECTS}

Starting from a context of distributed and collaborative interactions, we gave strategy areas of user interface distribution in the typical case of collaboration centered on an interactive table. A case study based on TangiSense and other surfaces made it possible to illustrate the strategies of distribution of the user interfaces. In order 
to distribute an interface given on two supports, it should be remembered that it can be seen as a set of interface elements (container / contained). In the particular case of tangible UI, an issue consists to define metaphors and adaptation rules to distribute Tangible interactors. It can thus be broken down and recomposed according to the context [7]. For this goal our perspectives are to define composition rules. The design and the evaluation of such new distributed interfaces open also many prospects for research.

Acknowledgments This research work was partially financed by the Ministère de l'Education Nationale, de la Recherche et de la Technologie $\square$, the 『région Nord Pas de Calais $\square$, the Centre National de la Recherche Scientifique $\square$, the FEDER, CISIT, and especially the Agence Nationale de la Recherche $\square$ (ANR TTT and IMAGIT projects ANR 2010 CORD 01701).

\section{References}

1. Blackwell, A., Fitzmaurice, G., Holmquist, L.E., Ishii, H., Ullmer, H. Tangible User Interfaces in Context and Theory workshop of CHI 2007, April 28 May 3, 2007, San Jose, California, USA.

2. Calvary, G., Coutaz, J., Thevenin, D., Limbourg, Q., Bouillon, L., Vanderdonckt, J.: A Unifying Reference Framework for Multi-Target User Interfaces. Interacting with Computers $15,3(2003) 289 \square 308$

3. Finkenzeller, K. (2003). RFID Handbook: Fundamentals and Applications in Contactless Smart Cards and Identification. John Wiley \& Sons, New York.

4. Kubicki, S., Lepreux, S., Kolski, C., and Caelen, J. (2010). Towards New Human-Machine Systems in contexts involving interactive table and tangible objects. 11th IFAC/IFIP/IFORS/IEA Symposium on Analysis, Design, and Evaluation of Human-Machine Systems, Valenciennes, France.

5. Kubicki S., Lepreux S., Kolski C. (2011). Evaluation of an interactive table with tangible objects: Application with children in a classroom. Proceedings 2nd Workshop on Child Computer Interaction "UI Technologies and Educational Pedagogy", at CHI'2011, Vancouver, Canada, may.

6 Lepreux S., Kubicki S., Kolski C., Caelen J. (2011). Distributed interactive surfaces using tangible and virtual objects. Proceedings Workshop DUI'2011 "Distributed User Interfaces", at CHI'2011, Vancouver, Canada, pp. 65-68, may, ISBN 978-84-693-9829-6

7. Lepreux S., Vanderdonckt J., Michotte B. (2006). Visual Design of User Interfaces by (De)composition. G. Doherty, A. Blandford, Proceedings of 13th Int. Workshop on Design, Specification and Verification of Interactive Systems DSV-IS'2006 (Dublin, 26-28 July 2006), Springer, LNCS, Berlin, pp. 157-170.

8 Melchior, J., Vanderdonckt, J., Van Roy, P. A Model-Based Approach for Distributed User Interfaces. ACM SIGCHI Symposium on Engineering Interactive Computer Systems (EICS 2011), Pisa, Italy, June 13-16, 2011..

9. Tandler, P. (2004). The BEACH Application Model and Software Framework for Synchronous Collaboration in Ubiquitous Computing Environments. Journal of Systems \& Software (JSS), Special issue on Ubiquitous Computing, 69(3):267.296. 